\title{
El surgimiento de "lo económico": acción y orden social dentro de la tradición económica
}

\author{
Javier Loyola Campos*
}

\begin{abstract}
Resumen
El artículo analiza y da cuenta del proceso de constitución de lo económico como un dominio independiente, dotado de una coherencia interna que le es propia, que permite la delimitación de un objeto de estudio particular y consecuentemente el surgimiento de una disciplina específica que lo aborde: la ciencia económica. Este proceso es importante para la sociología en tanto permite rastrear el origen de la solución que la economía "tradicional, "ortodoxa" o "liberal" da a uno de los problemas fundantes de la disciplina sociológica, a saber, el del vínculo entre acción y orden social. Se aborda la autonomización de lo económico siguiendo y ampliando el esquema de tres autores propuesto por Dumont (1999), con especial atención en la configuración progresiva de una determinada concepción respecto del actuar humano -el homo oeconomicus- y de una noción particular del orden social en íntima conexión con él -un orden espontáneo de mercado basado en el beneficio mutuo-.
\end{abstract}

Palabras claves: Acción económica - orden social - Locke - Mandeville - Smith.

\begin{abstract}
The article analyses and gives account of the process of constitution of economic field as an independent domain, endowed with an inner coherence of its own, which permits the delimitation of a particular object of study and consequently the emergence of a specific discipline to deal with it: economic science. This process is important to sociology as long as it allows tracking the origin of the solution that traditional economics gives to one of the main problems of sociology, namely, the link between social action and economic order. The paper addresses the independence of economic domain following and broadening the three-author scheme proposed by Dumont (1999), with special attention to the progressive configuration of a particular notion of human action -the homo oeconomicus- and a specific concept of social order in close relation to it -a spontaneous order based on mutual benefits-.
\end{abstract}

Keywords: Economic action - social order - Locke - Mandeville - Smith.

* Sociólogo, Universidad de Chile. Magíster en Ciencia Política con mención en Instituciones y Procesos Políticos, Pontificia Universidad Católica de Chile. Contacto: javierloyola@hotmail.com 


\section{INTRODUCCIÓN: EL POSTULADO DE LA COHERENCIA INTERNA DE LO ECONÓMICO}

La delimitación de un objeto de estudio particular, existente en tanto separado de otros campos, constituye la condición fundamental que debe cumplirse para que nazca una nueva disciplina científica. La historia del surgimiento de la denominada ciencia económica muestra que hubo de pasar largo tiempo para que al fin "lo económico" fuera reconocido como un dominio autónomo, independiente de otras materias. Antes de que se pudiera hablar de la economía como una ciencia plenamente constituida, ya eran objeto de reflexión problemas relativos a ciertos aspectos de la vida económica; sin embargo, estas cuestiones aparecían aún "sin relación o sólo débilmente ligadas entre sí, y eran tratadas no desde un punto de vista especial, sino desde una perspectiva más amplia" (Dumont, 1999: 46), en la que se encontraban implicados elementos de diversa índole (políticos, religiosos, etc.) en el análisis. La categoría de lo económico todavía no era "vista o sentida como un sistema, como constituyendo de algún modo un todo distinto de las otras materias" (Dumont, 1999: 45), y mientras ello persistiera no habría de ser posible que viera la luz la economía como una ciencia autosuficiente, es decir, que se bastara a sí misma en la explicación de los fenómenos económicos. El nacimiento de la ciencia económica como una disciplina autónoma exigía que el nuevo punto de vista se distinguiera plenamente de otros enfoques, y para que esto ocurriera debía ser reconocida la particularidad de su objeto de estudio, es decir, la coherencia interna que caracterizaría la esfera de lo económico.

Si bien la existencia separada de un objeto de estudio específico representa una condición que necesariamente debe darse para la conformación de cualquier disciplina científica, este proceso de delimitación de un campo particular en el caso de la ciencia económica ha revestido un carácter distintivo. El postulado de la coherencia interna del dominio que acompaña a la independencia del objeto de estudio no se reduce simplemente a la formulación de la interrelación lógica de las diferentes partes que componen el edificio económico, sino que tiene una implicación normativa fundamental, la que distingue a la ciencia económica de otras disciplinas: "el carácter distinto del dominio económico reposa sobre el postulado de una coherencia interna orientada al bien del hombre" (Dumont, 1999: 50), y se supone que esta coherencia es tal que los resultados más beneficiosos para todos se obtendrán si se abandona este dominio a sí mismo. Esta idea ha sido expresada a través del principio que Halévy (1934: 16) ha denominado como de la "identidad natural de los intereses", según el cual los individuos, por medio del intercambio y de la división social del trabajo, y sin saberlo o desearlo premeditadamente, contribuyen a la realización del interés general a través de la persecución racional de sus propios intereses. La instancia donde se concretaría esta coincidencia del interés particular con el interés general sería el mercado, el cual haría las veces de mecanismo de coordinación social articulador de las acciones económicas individuales motivadas por intereses privados, generando así no el caos, sino un orden lógicamente determinado (Schumpeter, 1971: 180). El postulado de la coherencia interna del dominio económico nos conduce de este modo a una determinada imagen del orden social, donde éste se entendería como "la consecuencia de la agregación de voluntades individuales, organizadas de manera espontánea por el mercado a medida que se suceden las relaciones de intercambio" (Figueroa, 2002: 22). En los planteamientos de la 
economía tradicional, el orden social se reduce a un orden espontáneo de mercado basado en los beneficios mutuos, cuyo funcionamiento libre de interferencias permitiría alcanzar un "óptimo social". Con esto se configura una particular visión de la sociedad humana, la cual se concibe como sostenida "íntegra y continuamente en lo que con frecuencia se denominan fuerzas económicas" (Hayek, 1982: 184).

La ciencia económica emerge sólo desde el momento en que lo económico es concebido como un sistema coherente; es únicamente a partir de ahí cuando se reconoce el dominio en su particularidad, en su diferencia respecto de otros campos de estudio, volviendo así imperativo el surgimiento de una disciplina específica que lo aborde. Al mismo tiempo que los economistas de la fase clásica formularon por vez primera esta coherencia interna, se convirtieron en defensores de la misma: se planteaba que ella traería consigo los mejores resultados posibles si se la dejaba obrar libremente. La constitución de lo económico como un todo coherente no ha sido para nada fácil; antes de que se iniciara la etapa de la "economía clásica", lo económico se encontraba fundido con la política y la moralidad, cuestión que impedía el surgimiento de una ciencia económica autónoma. Todavía no se pensaba este dominio como dotado de una coherencia interna que le era propia, sino que más bien se creía que esta coherencia debía ser asegurada desde el exterior, lo que se manifestaba en la imposición de una serie de regulaciones sobre la esfera económica y sobre la acción económica en particular. La configuración independiente y coherente de lo económico que hizo posible la emergencia de la ciencia económica exigía que el individuo fuera liberado de todas aquellas reglas que constreñían su conducta económica orientada a la búsqueda del propio beneficio, fueran éstas impuestas desde lo moral o desde lo político ${ }^{1}$. La emancipación de lo económico de estos dominios implica el reconocimiento de que el fin primordial de la vida es la satisfacción de las necesidades materiales, y de que esto sólo podría ser alcanzado si se dejaba a los individuos actuar libremente dentro del marco legal. Esto coincide con el argumento liberal según el cual los individuos disponen de la capacidad de razonar y son por lo tanto quienes están mejor capacitados para expresar y perseguir sus propios intereses sin la intervención de monarcas, aristócratas o sacerdotes (Holton, 1992: 52). Así, la ciencia económica que emerge de este proceso es liberal en la medida en que se adhiere al ideal de una sociedad conformada por individuos libres y autónomos, árbitros finales de "las decisiones u opciones acerca de su bienestar personal y de las acciones requeridas para alcanzarlo" (Holton, 1992: 54, traducción propia).

Durante la Edad Media, lo económico se encontraba subordinado a una moralidad fundada en la religión, cuestión que se expresaba en el sometimiento de las acciones económicas individuales a un conjunto de reglas morales impuestas por la autoridad religiosa. En la época medieval, "el criterio sobre la legitimidad de los actos no derivaba, por decirlo así, del solo concepto de ganancia, sino que aparecía determinado por reglas morales a que los principios económicos se subordinan" (Laski, 1987: 19). Estas reglas, de

"El origen y la evolución de la teoría económica moderna -señala Giannetti (2000: 120)- están íntimamente ligados a la construcción de un argumento riguroso sobre los costos, riesgos y límites de orden práctico asociados a un predominio excesivo de la autoridad y de la moralidad cívica sobre la acción individual". 
cuya observancia dependía la salvación del alma individual, resultaban incompatibles con el ideal secular de la búsqueda de la ganancia por sí misma, el cual hacia fines del Medioevo ya empezaba a impregnar la mentalidad colectiva de los seres humanos. La Iglesia trataba de imponer "un cuerpo de reglas para gobernar la vida económica, cuyo principio animador era el respeto al bienestar social en conexión con la salud del alma en la vida futura. Ante esta consideración, se estaba dispuesto a sacrificar el interés económico del individuo, puesto que ello aseguraba su destino celestial" (Laski, 1987: 23). En estas condiciones, el postulado de la coherencia interna de lo económico no hallaba cabida, ello porque aún no se configuraba la idea según la cual la búsqueda del enriquecimiento personal contribuye necesariamente al bienestar general; por el contrario, durante la Edad Media se atribuía a la Iglesia la función de resguardar este bienestar, y los preceptos morales por ella dimanados se pensaba que aseguraban el funcionamiento ordenado, coherente, de la esfera económica en tanto limitaban el accionar de los seres humanos prescribiendo tanto lo que los individuos podían adquirir como los medios que escogían para adquirirlo. Esta implicación entre lo económico y lo moral ciertamente tenía serias consecuencias sobre la manera en que se abordaba el análisis de los fenómenos económicos (véase Muller-Armack, 1967: 84-85).

La eliminación de la influencia de la autoridad religiosa sobre el dominio económico se encuentra íntimamente ligada a la revolución teológica que ha recibido el nombre de Reforma. Para ver de qué manera se produjo esto, es necesario examinar las consecuencias que tuvo este movimiento para la configuración independiente de lo político. La Reforma dio el impulso fundamental para la constitución autónoma de esta esfera; gracias a ella, "el dominio de la religión, que inicialmente es único y engloba todas las cosas, da origen a la categoría nueva, especial, de lo político, mientras que en el plano de las instituciones el Estado hereda sus rasgos esenciales de la Iglesia, a la que suplanta en tanto que sociedad global" (Dumont, 1999: 27). Durante la Edad Media, la Iglesia se imponía por sobre el Estado; éste "dispone en forma permanente sólo de una parte de sus funciones. La Iglesia no sólo es depositaria de la formación espiritual, del sistema escolar y de la política social sino que aspira también a la regulación de la vida económica y en una multitud de territorios ejerce el poder estatal mismo" (Muller-Armack, 1967: 75). La Reforma, al apuntar sus dardos contra el papado, sacude las bases del poder eclesiástico, lo que redunda en un cambio en la doctrina política: "se forma una teoría del Estado capaz de bastarse a sí misma" (Laski, 1987: 38). Este movimiento disocia el poder político de la base teológica que le servía de sustento, cuestión que deriva en la independencia de lo político respecto de lo religioso. El nuevo Estado ya no puede fundarse en la Ley Divina, sino que, por el contrario, debe hacerse autosuficiente: "surge entonces la moderna idea de la política, como esa actividad en la que el fin justifica los medios emancipándose, en función de la eficacia, de toda regla moral" (Naredo, 2003: 67).

La finalidad principal que se propuso el Estado moderno fue la mantención del orden, en la medida en que éste ya no podía ser pensado como sostenido por fuerzas religiosas. Una vez logrado esto, "las diferencias entre los hombres se refieren a problemas fundamentalmente económicos sobre lo que ese orden hace, a la réplica, en suma, del Estado a los derechos que reclaman los poseedores de la propiedad, y el criterio de la réplica, a estas alturas, ya no es 
el del derecho divino. Es el de una concepción de utilidad en relación al bienestar material. La idea del logro de la riqueza como fin social básico se ha convertido en la piedra angular de la actividad política" (Laski, 1987: 47). Tal como apunta Muller-Armack (1967: 104), "los ideales económicos secularizados de la época colman la idea del Estado", lo que significa el desplazamiento del foco de atención desde los intereses celestiales hacia los intereses terrenales de los seres humanos, expresados estos últimos en la búsqueda incesante del enriquecimiento personal (véase Naredo, 2003: 47-48).

Uno de los resultados que produjo la Reforma fue así la destrucción del poder de la Iglesia sobre la esfera económica, la cual ahora se ve liberada de las consideraciones teológicas que la encadenaban durante el periodo medieval. Sin embargo, el Estado secular que surge producto de este movimiento hereda de la institución eclesiástica sus pretensiones totalizantes; ahora se le atribuye a él, no ya a la Iglesia, la función de fijar las normas de la conducta económica. El Estado había logrado la paz, por tanto se consideraba natural también arrogarle la tarea de asegurar la prosperidad material del conjunto de la sociedad. El bienestar social no se pensaba como el resultado de la libre interacción entre individuos que persiguen sus intereses personales; por el contrario, en aquella época se consideraba "al Estado como el gran regulador de cuya benéfica acción podía brotar la abundancia" (Laski, 1987: 53). La coherencia de lo económico se aseguraba ahora desde lo político, y no ya desde una moralidad fundada en la religión, tal como sucedía en la Edad Media. Reflejo de esta particular situación es la corriente de pensamiento económico que se conoce como mercantilismo, cuya característica principal es precisamente la consideración de "los fenómenos económicos desde el punto de vista de la política" (Dumont, 1999: 46).

La falta de coherencia interna de lo económico que se observa en la etapa mercantilista se debe en gran medida a que en aquella época todavía no se había instalado una noción moderna de producción. Antes del advenimiento de la ciencia económica no se otorgaba un papel central a los seres humanos en la producción de riquezas; "nada se consideraba que fuera producido por el hombre; las riquezas se veían bajo el prisma de las mitologías como fruto de un maridaje entre el Cielo y la Tierra (...) Los hombres trataron todo lo más de propiciar esa creación originaria acelerándola, emulándola a través del rito pero raramente esperaban que se pudiera alterar de forma esencial el ritmo de producción de las riquezas y menos aún provocar una aceleración indefinida del mismo" (Naredo, 2003: 74). Se creía que la actividad de los seres humanos se limitaba a la apropiación de las riquezas que "la naturaleza o la gracia divina ponían a su disposición pudiendo, eso sí, 'mudar' su sustancia hacia las formas que le resultaran más convenientes y que también podían ser objeto de comercio" (Naredo, 2003: 76). Mientras predominara esta noción arcaica de producción, afirma Naredo (2003: 76), "sólo cabía pensar que la acumulación de riquezas, ya fuera por Estados o por individuos, tenía que proceder en lo fundamental de la adquisición de las riquezas de otros territorios o de otras personas mediante el expolio colonial y la práctica habilidosa del comercio, tareas éstas que, se pensaba, el Estado debía de encauzar adecuadamente mediante un uso afortunado de la política, las armas militares y los controles militares y financieros". Si la obtención de riquezas dependía de estas artimañas políticas, idea que a su vez era resultado de la vigencia de un concepto anticuado de producción, 
entonces era inevitable que el comercio o el intercambio se viera "como un juego en el que las ganancias obtenidas por ciertos Estados o individuos mediante la habilidad, el engaño o la coerción, se traducían inevitablemente en pérdidas para otros" (Naredo, 2003: 78), lo que denota claramente que lo económico durante el periodo mercantilista no era concebido como un espacio dotado de coherencia interna en la medida en que esta coherencia le debía ser impuesta desde lo político.

La formulación del postulado de la coherencia interna de lo económico requería que la idea, propia del mercantilismo, según la cual "en el comercio el beneficio de una parte implicaba la pérdida de la otra" (Dumont, 1999: 49), fuera desplazada en favor de una noción que entendiera el intercambio como beneficioso para las dos partes que intervienen en él; "considerar el intercambio como ventajoso para las dos partes -sostiene Dumont (1999: 49) - representa un cambio fundamental, y señala la emergencia de la categoría económica", y junto con ello de una ciencia que reclama exclusividad sobre el nuevo objeto de estudio así constituido. Las interpretaciones mercantilistas "resultaban incompatibles con la creencia en la posibilidad de un progreso extensivo a toda la humanidad y no a un puñado de metrópolis coloniales" (Naredo, 2003: 79), creencia que iba a caracterizar a la moderna ciencia económica. Esta disciplina reposa sobre el postulado de la coherencia interna de su objeto de estudio; en el mercantilismo esta coherencia le era atribuida desde lo político, en el sentido de que la ganancia únicamente podía ser asegurada por el Estado. De este modo, lo que muestra la literatura mercantilista es que "para que un dominio separado pudiera ser reconocido un día como económico, debía ser arrancado del dominio político; el punto de vista económico pedía ser emancipado del punto de vista político" (Dumont, 1999: 49). Para entender el cómo se llegó a concebir esta idea de la coherencia interna de lo económico es entonces necesario poner atención al proceso a través del cual lo económico se emancipó no sólo de lo político, sino también de la moralidad. Este proceso es a su vez inseparable del desarrollo de conceptos modernos de producción y riqueza que resultaran adecuados para dotar de coherencia a la esfera económica.

Llegados a este punto cabe preguntarse: ¿qué importancia, si es que la tiene, puede revestir dicho proceso para el desarrollo de la sociología? El atender a la autonomización de lo económico permite observar cómo va tomando forma la respuesta que la economía "ortodoxa" o "liberal" da a uno de los problemas fundantes de la disciplina sociológica: el vínculo entre acción y orden social. Y es que la constitución de lo económico como un dominio independiente y coherente corre pareja a la conformación de una determinada concepción respecto del actuar humano, así como también a la configuración de una noción particular del orden social en íntima conexión con él. La economía tradicional contempla el dominio económico como una realidad ordenada que es el producto emergente del enfrentamiento de una multiplicidad de individuos que, en tanto homo oeconomicus, buscan a través de sus acciones sólo defender lo que consideran que es su propio interés. En el subsistema económico se resolvería de este modo el problema de la coordinación social, y por ende el del orden societal, en virtud del mecanismo del mercado regido por el sistema de precios (Giannetti, 2000: 127).

Es así como el presente artículo tiene como objetivo central el de explicitar el camino que tuvo que recorrerse para que lo económico llegara a constituirse como un dominio 
independiente dotado de una coherencia interna que le era propia, ello en la medida en que atender a este proceso permite comprender el origen de la solución que la corriente económica predominante da al problema del orden social, la cual ha planteado grandes desafíos a la sociología al mismo tiempo que ha influido enormemente en su desarrollo, en especial sobre aquellas corrientes sociológicas de corte individualista. Se plantea, siguiendo a Dumont (1999: 45), que la emancipación completa de lo económico tanto de lo político como de lo moral así como también la formulación de conceptos modernos de producción y riqueza, todas estas condiciones necesarias para que dicho dominio adquiriera una existencia independiente y coherente, se dieron en la principal obra de Adam Smith. Ahora bien: estas cuestiones no se dieron automáticamente con este autor, y es así como Dumont propone ciertos autores que antes de Smith habían avanzado ya en la dirección de la autonomía de lo económico, delimitando de este modo el objeto de estudio de la ciencia económica. La autonomización de lo económico habría procedido por etapas, desde su separación de lo político (Locke), luego de la moralidad (Mandeville), hasta finalmente adquirir plena independencia y coherencia (Smith). Acá se sigue este esquema secuencial propuesto por Dumont, al mismo tiempo que se intenta ampliar su análisis.

\section{LOCKE Y LA EMANCIPACIÓN DE LO ECONÓMICO DE LO POLÍTICO}

Para entender la relevancia que reviste Locke para la constitución de lo económico es preciso ver el lugar que en su teoría ocupa la noción de propiedad. Esta categoría ciertamente ocupa un lugar central, y toda la teoría política lockeana se basa en ella; de hecho, "el fin supremo y principal de los hombres al unirse en repúblicas y someterse a un gobierno es la preservación de sus propiedades" (Locke, 1997: 293), y "esta proposición exige evidentemente el postulado de que los hombres tienen un derecho natural a la propiedad: un derecho anterior a la existencia de la sociedad y el gobierno civiles, o independientemente de éstos" (McPherson, 1979: 197). Pero, ¿qué entiende Locke específicamente por propiedad? Locke no sólo concibe la propiedad en su sentido estricto (es decir, económico, como propiedad sobre los bienes y la tierra), sino que le otorga un significado más amplio, que incluye la propiedad que los individuos tienen sobre su vida y su libertad. Más allá de la confusión que esta definición ambigua puede acarrear, Locke, "tanto cuando usa 'propiedad' en sentido amplio como cuando la emplea en sentido estricto, clasifica los bienes al lado de la vida como objetos del derecho natural de los hombres, objetos para cuya salvaguarda crean éstos los gobiernos" (McPherson, 1979: 197).

Locke nos presenta un estado de naturaleza donde todos los seres humanos son libres e iguales; el estado de naturaleza es "un estado de igualdad, dentro del cual todo poder y toda jurisdicción son recíprocos, sin que nadie tenga más que otro, puesto que no hay nada más evidente que el que las criaturas de la misma especie y rango, nacidas en total promiscuidad, para disfrutar de las mismas ventajas naturales y emplear las mismas facultades, deberían ser iguales entre sí, sin subordinación ni sujeción alguna" (Locke, 1997: 205). Por otra parte, este estado es también un estado de perfecta libertad donde los seres humanos pueden "ordenar sus acciones y disponer de sus pertenencias y personas según estimen conveniente, dentro de los límites impuestos por la ley natural, sin necesidad de pedir licencia ni depender de 
la voluntad de otra persona" (Locke, 1997: 205). La ley natural es la que hace posible el orden en el estado de naturaleza. Es ella la que impide que el estado de libertad en que se encuentran los seres humanos degenere en un estado de absoluta licencia; "el estado de naturaleza tiene una ley natural que lo gobierna y que obliga a todo el mundo. Y la razón, que es esa ley, enseña a todos los hombres que se molesten en consultarla que al ser todos iguales e independientes, nadie puede perjudicar a otro en su vida, salud, libertad o posesiones" (Locke, 1997: 206-207). De este modo, los individuos serán racionales en la medida en que orienten sus acciones conforme a los dictados de la ley de la naturaleza.

Al ser todos los seres humanos naturalmente iguales, todos ellos tendrían un derecho natural a las posesiones, "además de un derecho natural a la vida, a la salud y a la libertad" (McPherson, 1979: 198), al mismo tiempo que se verían impedidos, por dictamen de la misma ley natural, a entrometerse en la propiedad de otros. Lo relevante en este punto es cómo Locke fundamenta el derecho natural a la propiedad económica, es decir, a la propiedad sobre los bienes y la tierra. Como ya se dijo, el estrato humano se caracteriza por la igualdad; por otra parte, "entre hombres y no-hombres se trata de un asunto de propiedad" (Dumont, 1999: 73). Así, para que los seres humanos puedan realmente disfrutar de los frutos de la naturaleza, y con esto satisfacer el derecho natural que todos tienen a su propia conservación, es decir, a alimentarse y mantenerse, "es preciso que exista algún medio para apropiarse de ellos" (Locke, 1997: 223), sacándolos así del estado común en que se encuentran, pues "antes de que un hombre cualquiera pueda utilizar algo del producto natural de la tierra para alimentarse o mantenerse, ha de apropiárselo" (McPherson, 1979: 199), o sea, "ha de ser suyo; tan suyo, esto es, tan parte de él mismo, que nadie puede tener ningún derecho sobre él, hasta que no le haya servido de sustento para su vida" (Locke, 1997: 223). Locke fundamenta este derecho individual a la apropiación en el trabajo: "cada hombre es propietario de su propia persona, sobre la cual nadie, excepto él mismo, tiene ningún derecho. Podemos añadir a lo anterior que el trabajo de su cuerpo y la labor de sus manos son también suyos. Luego, siempre que coja algo y lo cambie del estado en que lo dejó la naturaleza, ha mezclado su trabajo con él y le ha añadido algo que le pertenece, con lo cual, lo convierte en propiedad suya" (Locke, 1997: 223).

El trabajo es así lo que distingue lo propio de lo que es común. Algo será mío en la medida en que mezcle con ello mi trabajo. El mismo procedimiento utiliza Locke para justificar la apropiación individual de la tierra; "la medida de su propiedad vendrá fijada por la cantidad de tierra que un hombre labre, siembre, cuide y cultive" (Locke, 1997: 226), es decir, por la cantidad de tierra a la que el individuo incorpore su trabajo. De este modo, "a partir de los dos postulados, que los hombres tienen derecho a conservar su vida, y que el trabajo de un hombre es propiedad suya, justifica Locke la apropiación individual del producto de la tierra originalmente entregado a la humanidad en común" (McPherson, 1979: 199), así como también de la tierra misma.

La apropiación individual, tanto de la tierra como de los productos de la misma, está sujeta a ciertas limitaciones impuestas por la misma ley natural que la justifica a través de los dos postulados mencionados anteriormente (Locke, 1997: 225-226). De aquí que la 
interpretación común de la obra de Locke señale que el alegato de éste es en favor de una propiedad individual limitada. McPherson (1979: 198) cuestiona esta interpretación cuando afirma que lo que Locke realmente defiende es un derecho natural ilimitado a la apropiación; "la asombrosa hazaña de Locke consistió en fundamentar el derecho de propiedad en el derecho natural y en la ley natural, y en eliminar luego todos los límites del derecho natural para el derecho de propiedad". La consideración de cómo el filósofo inglés habría hecho esto deja en evidencia el gran paso que habría dado este autor en la constitución de lo económico: su independencia respecto de lo político.

Una de las limitaciones que Locke impone explícitamente a la apropiación individual es la siguiente: "podrá fijarse la propiedad sobre algo mediante el trabajo, en la medida en que se puede obtener de ello algún provecho antes de que se malogre. Todo aquello que sobrepase este límite, supera a la parte que corresponde a una persona y pertenece a otros. Dios no creó nada para que el hombre lo malograra o lo destruyera" (Locke, 1997: 226). Resulta clara la vinculación entre esta limitación y la ley natural: el acaparamiento más allá de lo que resulta necesario para la satisfacción de las propias necesidades atentaría contra el derecho natural de los demás individuos a su propia conservación, ello en tanto lo que se malogra podría haber servido a otros para alimentarse y mantenerse. Locke pensaba, según señala McPherson (1979), que esta limitación quedaba ampliamente trascendida, aunque no negada, desde el momento en que los seres humanos acuerdan el uso del dinero. "Alguien traspasa los límites de lo que le corresponde en justa propiedad no por acaparar muchas cosas, sino por permitir que se le estropeen inútilmente en su poder" (Locke, 1997: 238); que esta última situación no ocurriera iba a depender de la introducción de algo no degradable que pudiera ser recibido a cambio de la cantidad de producto que excedía las necesidades de su poseedor. Fue de esta manera "como se llegó a utilizar el dinero, es decir de algo duradero que los hombres pudieran guardar sin que se pudriera y que, por consenso mutuo, se pudiera utilizar en los trueques a cambio de artículos verdaderamente útiles (aunque perecederos) para el sustento de nuestras vidas" (Locke, 1997: 238). El deseo de tener más de lo que se necesita se justifica si el producto sobrante se intercambia por oro y plata, metales que nunca se echan a perder y que, "por consiguiente, pueden ser acumulados justamente en cantidades ilimitadas" (McPherson, 1979: 202-203), sin perjudicar a nadie ${ }^{2}$.

Lo importante aquí es cómo concibe Locke el consenso que introduce el uso del dinero. Según McPherson, este consenso es radicalmente distinto del consenso que introduce a los seres humanos en la sociedad civil; "el consentimiento del dinero es anterior al consentimiento de la sociedad civil e independiente de él" (McPherson, 1979: 207). Antes del dinero, los

2 De este modo, afirma McPherson (1979: 206), "Locke muestra lo que el dinero ha hecho posible: precisamente que un hombre pueda acumular más tierra que aquella cuyo producto podía usar antes de que se echara a perder. Los límites del derecho natural original no son negados. Sigue siendo contrario al derecho natural apropiarse de una cantidad de productos parte de la cual (o parte de otras cosas obtenidas mediante trueque de las primeras) se echará a perder antes de que pueda ser consumida. Y sigue siendo contrario a la ley natural apropiarse de una cantidad de tierra parte de cuyo producto (o de su trueque) se echará a perder antes de que se pueda consumir. Pero ahora es posible cambiar cualquier cantidad de producto por algo que jamás se echa a perder". 
seres humanos no se esforzaban por tener más de lo necesario para su sustento; de nada les servía a ellos aumentar sus posesiones de tierras más allá de aquellas que le bastaban para la satisfacción de sus necesidades. Sólo cuando se introduce el dinero prende en los seres humanos el deseo de acumular más tierras de las necesarias ya que el excedente que éstas arrojaran podía ser ahora llevado al mercado e intercambiado por medio de este recurso. Fue mediante el consenso del dinero como se encontró "la manera por la que un hombre puede llegar a poseer más tierra de la que puede llegar a hacer uso, recibiendo a cambio de su excedente una cantidad de oro y plata que se puede almacenar sin causar ningún tipo de perjuicio a nadie, puesto que estos metales no se estropean en manos de su poseedor. Este reparto de cosas en posesiones privadas desiguales ha sido posible fuera de los límites de la sociedad y sin necesidad de pacto, con sólo poner valor al oro y la plata y llegar al acuerdo tácito del uso del dinero" (Locke, 1997: 239-240). De esta manera, el consenso tácito y voluntario del dinero queda establecido en el estado de naturaleza, al igual que la posesión desigual de tierras y el comercio que son su consecuencia.

La idea de la existencia de comercio en el estado de naturaleza es una idea radical, y apunta en el sentido de la independencia de lo económico respecto de lo político. La factibilidad de esta economía mercantil existente con independencia del poder político la fundaría Locke en el postulado de la racionalidad de los seres humanos; ellos serían lo suficientemente capaces de guiar su acción por los dictados de la ley natural, lo que los llevaría a respetar los derechos naturales de los demás. Dado esto, sería "perfectamente comprensible que esos hombres acuerden no solamente atribuir un valor al dinero sino también aceptar un código de honestidad comercial que haga posible una amplia economía comercial sin establecer un poder civil formal" (McPherson, 1979: 207-208). A juicio de McPherson (1979: 208), "Locke puede suponer que ni el dinero ni los contratos deben su validez al Estado, que son creación de las finalidades naturales de los hombres y que deben su validez a la razón natural de éstos. Según esta concepción, lo que fundamenta el valor convencional del dinero y la obligatoriedad de los contratos comerciales es la postulada razonabilidad moral de los hombres por su naturaleza misma y no la autoridad de un gobierno".

Locke no habría podido concebir la idea de una economía mercantil en el estado de naturaleza si no hubieran estado presentes en su obra conceptos adecuados de producción y riqueza. En primer lugar, la importancia que el filósofo inglés otorga a la noción de trabajo apunta en la dirección de una nueva concepción de la relación ser humano-entorno, que dejaría sentadas las bases para el desarrollo de un concepto moderno de producción: a los seres humanos se les atribuye ahora la capacidad de someter a la naturaleza para su propio beneficio mediante su trabajo, desplazando así la noción tradicional donde éstos asumían una actitud pasiva frente a su medio ambiente, la cual, como ya se dijo, predominaba en la etapa mercantilista. Por otra parte, destaca en Locke la preeminencia de la riqueza mobiliaria sobre la inmobiliaria: la introducción del dinero da lugar a una amplia economía mercantil al permitir que los individuos intercambien aquella parte del producto que excede sus necesidades. Además, el dinero puede ser acumulado en cantidades ilimitadas pues corresponde a un tipo de sustancia que nunca se echa a perder en manos de su poseedor. Esta perspectiva de acumulación ilimitada que abre el dinero incita a los seres humanos a 
trabajar y producir más allá de sus necesidades, pudiendo intercambiarse los excedentes en el mercado. De este modo, las nociones de producción y riqueza contenidas en la obra de Locke, tomadas conjuntamente, dan forma a un espacio económico dotado de cierta coherencia, en el cual las relaciones de intercambio resultan ser ventajosas para todos los que participan de ellas. Esto volvería marginal la intervención estatal en la esfera económica, la que durante el periodo mercantilista se consideraba fundamental a la hora de asegurar el beneficio.

Entender el espacio económico como existiendo con anterioridad al dominio político supone tomar como punto de partida al individuo y su propiedad, y el fundamento de esta última se encuentra nada más y nada menos en lo que de modo más íntimo pertenece a cada persona: su vida y su trabajo. Con la introducción del dinero los límites iniciales impuestos al derecho de propiedad son trascendidos, por tanto el individuo queda en libertad para apropiarse de más de lo que necesita e intercambiar el excedente por otros productos útiles para la vida. Dumont (1999: 86) afirma que en la obra de Locke se observa el triunfo de una concepción individualista sobre una holista, o, lo que es lo mismo, la victoria de una visión centrada en las relaciones entre los hombres y las cosas, y por tanto en las necesidades materiales, sobre otra focalizada en las relaciones entre los seres humanos, las cuales no serían otra cosa que derivados de esta primera relación primordial. En la medida en que las relaciones de intercambio, es decir, aquellas en que se involucran los individuos propietarios para satisfacer sus necesidades materiales, reportan beneficios para todas las partes intervinientes, la intervención desde la esfera política es mínima. Es cierto que en los planteamientos lockeanos, tal como apunta McPherson (1979), se encuentra presente la idea de una economía mercantil regida por el dinero que existe en el estado de naturaleza con independencia de la autoridad de un gobierno. Ahora bien: resulta extremadamente difícil imaginar que algo así realmente pueda suceder. La presencia de esta idea en la obra de Locke puede interpretarse más bien como una manera de la que se vale este autor para destacar que en último término lo económico no se sustenta en lo político. A los gobiernos, a diferencia de lo que ocurría en el periodo mercantilista, ya no les corresponde imponer activamente regulaciones a la vida económica; se supone que esta esfera constituye una realidad coherente, y que la intervención política de la autoridad debe limitarse solamente a la protección de las propiedades de los individuos, sin que le estuviera permitido prescribir lo que cada uno podía o no podía hacer con lo que era suyo. Lo político queda así subordinado a lo económico: las relaciones en que entran los seres humanos entre sí en el plano político persiguen la salvaguarda de aquello que los individuos obtuvieron legítimamente mediante su trabajo. Se configura de esta forma la imagen de una sociedad que halla su sustento en lo económico: "la sociedad se convierte en un hato de individuos libres e iguales relacionados entre sí como propietarios de sus propias capacidades y de lo que han adquirido mediante su ejercicio. La sociedad está hecha de relaciones de intercambio entre propietarios" (McPherson, 1979: 15).

Hay contenida en la obra de Locke una primera formulación de la coherencia interna de lo económico en la medida en que se entiende que el bienestar general es alcanzable con sólo dejar que los individuos persigan libremente sus fines privados. El Estado lockeano, 
comparado con el Estado absoluto del mercantilismo, ve reducidas dramáticamente sus atribuciones, y ya no le corresponde asegurar la coherencia de lo económico. Locke habría facilitado "una teoría de la propiedad que hacía a sus dueños dignos de protección por razón del esfuerzo que su acumulación implicaba y del bien social que esto representaba" (Laski, 1987: 102). Sin embargo, en las formulaciones del filósofo inglés la coherencia de esta esfera económica concebida independientemente de lo político no se funda en la pura articulación de las acciones económicas individuales movidas por una racionalidad utilitaria, y la explicación de este hecho se encuentra en la manera como Locke concebía a los seres humanos, que a su juicio eran en esencia racionales y sociales: "Racionales, pues podían vivir juntos por la ley natural, que es la razón o que al menos (sin hallarse impresa en la mente) es cognoscible mediante la razón, sin la ayuda de la revelación. Y sociales al poder vivir según las leyes de la naturaleza sin que un soberano les impusiera reglas de conducta" (McPherson, 1979: 234).

La armonía de los intereses, y con ello la coherencia de lo económico, es posible en virtud de este postulado, el cual implica la subordinación de la racionalidad utilitaria a una racionalidad de tipo moral. El funcionamiento de una economía mercantil donde cada individuo busca obtener el máximo beneficio se sustenta en último término gracias a la conformidad de la acción económica a las prescripciones de la ley natural. Si la coherencia de lo económico es viable, ello es porque los seres humanos, siendo racionales como Locke supone que son, son capaces de ceñir la búsqueda del lucro personal a ciertas reglas cuyo contenido está inscrito en la ley de la naturaleza, y que consiste en respetar los derechos naturales de los demás. Esto asegurará que en la persecución de sus fines económicos los seres humanos no traten de destruirse mutuamente. Puede concluirse entonces que la coherencia de lo económico, que en el mercantilismo era impuesta desde lo político, en Locke se le confiere a este dominio desde un tipo particular de moralidad fundada en el derecho natural. El individuo aquí se encuentra sujeto a normas que ligan su acción económica a un orden trascendente, lo que nos conduce sólo a una coherencia a medias de lo económico, que no es la misma que la plena coherencia que encontramos en la obra de Smith, donde este dominio se halla desgajado tanto de lo político como de lo moral.

El dominio económico es concebido en Locke como un espacio donde conviven racionalidad moral y racionalidad utilitaria; la preeminencia de la primera respecto de la segunda es indicativa de una implicación entre lo económico y la moralidad. Esta coherencia a medias de lo económico conduce a una imagen del orden social entendido principalmente como un orden moral, no como un orden instrumental basado en el puro interés tal como lo iba a entender la economía una vez constituida plenamente. La formulación de la coherencia integral de lo económico exigía la emancipación de este dominio del ámbito moral; sólo cuando ello ocurriese se daría un impulso definitivo para la conformación de la ciencia económica. La acción económica no podía ya seguir juzgándose en virtud de su conformidad o disconformidad respecto de los preceptos a priori de la filosofía del derecho natural. "Hay en la teoría del derecho natural -afirma Dumont (1999: 102)-, como en la moralidad tradicional, una referencia trascendente fundamentalmente normativa que desaparece en la filosofía utilitarista, y que es reemplazada en ella por un criterio inmanente, 
empírico, a saber, la máxima felicidad del mayor número". El desplazamiento desde una filosofía iusnaturalista hacia el utilitarismo representaba un paso que forzosamente debía darse para que emergiera la ciencia económica; esta disciplina, en tanto ciencia, no podría ver la luz mientras lo económico permaneciera ligado a una ética trascendente como la que se manifiesta en la filosofía social de Locke. La acción económica debía liberarse de toda referencia supraterrenal, y fue precisamente el utilitarismo el que supo satisfacer esta condición; "el punto de partida del utilitarismo es que la conducta humana debe juzgarse moralmente de acuerdo con sus resultados o, más específicamente, de acuerdo con sus efectos sobre la balanza de la felicidad humana general" (Myrdal, 1961: 53). El utilitarismo nos presenta así una "ética naturalista" cuyo lema es el siguiente: "es buena toda acción que promueve el bien social, es mala toda aquella que lo perjudica" (Schumpeter, 1971: 135).

La transición hacia el utilitarismo, filosofía en la que se halla contenida una particular visión de la naturaleza humana en conjunto con una ética de carácter empírico, se observa en la obra de Mandeville, razón por la cual puede decirse que este autor dio un paso fundamental en la emancipación de lo económico respecto de la moralidad.

\section{MANDEVILLE Y LA EMANCIPACIÓN DE LO ECONÓMICO DE LO MORAL}

Se ha dicho que lo económico debía liberarse no sólo de lo político, sino también de lo moral, para así constituirse como un dominio autónomo y plenamente coherente. Ahora bien: ¿es correcta esta fórmula? ¿Es correcto decir que en un momento dado lo económico se emancipó de lo moral? No es del todo adecuado hablar en estos términos, sostiene Dumont (1999: 87), "pues en este caso la relación es más sutil. Hay ciertamente emancipación por lo que se refiere al curso general y común de la moralidad, pero va acompañada por la noción de que la acción económica está por sí misma orientada hacia el bien, que posee un carácter moral que le es especial; en virtud de ese carácter especial se le permite escapar a la forma general del juicio moral. En suma, habría sólo una especialización de la moral, o con más exactitud: lo económico sólo consigue escapar a las trabas de la moralidad general asumiendo en sí mismo un carácter normativo propio". Acá se sostiene, junto con Dumont, que esto se produjo con Mandeville, y ello es perceptible en el postulado central de su obra.

Mandeville comienza su obra principal, denominada La fábula de las abejas, con un breve poema que lleva por nombre "El panal rumoroso o la redención de los bribones". En él se relata la historia de una colmena, reflejo de la sociedad humana, donde reina el vicio, pero que no obstante goza de la más completa prosperidad. Sin embargo, a las abejas no les gustaba ver mezclado este bienestar con sus acciones viciosas, y por ello ruegan a Dios para que les conceda la virtud. Una vez que Dios accede a este deseo, se sucede una gran transformación: la colmena, ya liberada del vicio, cae en la inactividad y la pobreza. De aquí se deriva la tesis principal del poema, que Mandeville se encarga de desarrollar con mayor profundidad en el resto del libro, según la cual "el vicio es el fundamento de la prosperidad y la felicidad nacionales" (Kaye, 1982: xxix).

Cabe preguntarse ahora qué significa que una acción sea virtuosa o viciosa. Kaye, en su introducción al pensamiento de Mandeville, afirma que la definición que este autor da 
de virtud fue "un reflejo de las dos magnitudes corrientes del pensamiento de su época, ascética una, racionalista la otra. Según la primera -una posición teológica común-, la virtud es la trascendencia de las exigencias de la corrompida naturaleza humana, la conquista de sí mismo que se logrará por la gracia divina. Según la segunda, la virtud es la conducta ordenada por la mera razón" (Kaye, 1982: xxix-xxx). Ambas corrientes hacen alusión a una moral de tipo trascendente. De la amalgama de ambas concepciones resulta que Mandeville (1982: 27) Ilama virtud "a cualquier acto por el cual el hombre, contrariando los impulsos de la Naturaleza, procurara el bien de los demás o el dominio de sus propias pasiones mediante la racional ambición de ser bueno". Según este criterio, la acción es moralmente buena o virtuosa en tanto se oriente deliberadamente hacia el bien ajeno o hacia el bien público. Por otra parte, el vicio corresponde "a todo lo que el hombre, sin consideración por el público, fuera capaz de cometer para satisfacer alguno de sus apetitos" (Mandeville, 1982: 27), lo cual implica que una acción viciosa es siempre una acción egoísta. A esta mezcla de ascetismo y racionalismo presente en la definición mandevilliana Kaye la denomina "rigorismo".

Mandeville describe al ser humano como un animal dominado por sus pasiones; "concibo al hombre como un compuesto de varias pasiones y que todas, a medida que se las provoca y van saliendo a la superficie, lo gobiernan por turno, quiéralo o no" (Mandeville, 1982: 22). La vida de los seres humanos consiste en un esfuerzo constante por satisfacer estas pasiones. Tal como afirma este autor, "es imposible que el hombre. (...) pueda actuar con otro objetivo que el de satisfacerse a sí mismo" (Mandeville, 1982: 233), y esta satisfacción siempre se lleva a cabo sin ninguna consideración por el bienestar de los demás. De este modo, sus planteamientos conducen a una particular visión de la naturaleza humana, cuyo componente central es el egoísmo de los seres humanos. Dada esta característica, resulta imposible que cualquier acción humana, especialmente la acción económica, pueda ajustarse a la definición rigorista de virtud, ello en tanto actuar virtuosamente según esta fórmula significa actuar de forma generosa y desapasionada. Mandeville creía fervientemente que, en el mundo real, ninguna acción satisface los criterios rigoristas. No habría encontrado, "buscando en todo lo que quiso, ninguna acción -ni entre las más laudables- dictada exclusivamente por la razón y completamente exenta de egoísmo" (Kaye, 1982: xxx). Si no existen acciones que no tengan un fondo egoísta, incluso las que en apariencia son altruistas, entonces la totalidad de ellas serían, según la misma fórmula rigorista, viciosas, en el sentido de que no se orientan desinteresadamente hacia el bien de los demás, y "de aquí es sólo una deducción obvia que, si todo es vicioso, también las cosas provechosas para nosotros proceden de causas viciosas, y los vicios privados son beneficios públicos" (Kaye, 1982: xxx) ${ }^{3}$.

3 Aquí cabe apuntar que no todos los vicios son benéficos: "cuando afirmo que los vicios son inseparables de las sociedades grandes y poderosas y que sin ellos no podrían subsistir su riqueza ni su grandeza -dice Mandeville (1982: 9)-, no quiero decir que cada miembro de ellas, que sea culpable de algún vicio, no deba ser continuamente castigado por ellos, cuando se convierten en delitos". De esta manera, debe hacerse la distinción entre dos tipos de vicios: los vicios útiles y los vicios dañinos. Los primeros constituyen la base de las sociedades prósperas, y ellos no deben reprimirse, mientras que los segundos son crímenes y deben ser sancionados por el Estado. Nuevamente, como en Locke, encontramos aquí la idea de un Estado limitado en sus atribuciones en tanto éste en los planteamientos mandevillianos se reduce a una mera agencia policíaca. 
En Mandeville conviven dos maneras de juzgar las acciones humanas: una derechamente utilitarista y otra antiutilitarista. La primera evalúa las acciones atendiendo a sus consecuencias sobre la prosperidad y felicidad nacionales, mientras que la segunda las califica en virtud de la motivación que las origina: "así, solamente son virtuosos aquellos actos que provienen de motivos que cumplen con las exigencias del rigorismo" (Kaye, 1982: xxxi). Mandeville, tal como señala Kaye, inclina abiertamente sus simpatías por el criterio empírico, es decir, utilitarista, de evaluación de la conducta, sin abandonar eso sí el credo rigorista. Para este autor lo más importante es la consecución del bien público, el cual se identifica manifiestamente con la prosperidad material o económica. La observación de la realidad muestra que este fin sólo es alcanzable a través de acciones que de acuerdo al rigorismo son viciosas; de este modo, la acción contraria a la norma moral, es decir, aquella que es egoísta o viciosa, queda ampliamente justificada gracias a los resultados sociales positivos que ella arroja. Si "todos los beneficios están basados en acciones fundamentalmente viciosas" (Kaye, 1982: xlviii), entonces, siguiendo el argumento mandevilliano, "la pretensión de la moral es falsa en la medida en que de hecho no es mediante ella como se alcanza el bien público" (Dumont, 1999: 100). Por más que esta moral trascendente prescriba una acción virtuosa, es decir, deliberadamente orientada a procurar el bien de los demás, en los quehaceres de este mundo los seres humanos nunca actúan de esta manera dada su particular naturaleza egoísta. Incluso si pudieran llegar a actuar así, sólo cabría esperar de ello la inactividad y la pobreza: "si se suprimieran todos los actos, salvo los debidos al desinterés, a la idea pura de bondad o al amor de Dios, cesaría el comercio, las artes se harían innecesarias y la mayoría de los oficios quedarían abandonados" (Kaye, 1982: xxx). Mandeville, sostiene Kaye, "ocupó la mayor parte de su libro en demostrar que una vida regulada por la virtud rigorista, como se expresa en su definición, no solamente es imposible sino sumamente indeseable" (Kaye, 1982: Ixix). El utilitarismo de Mandeville (1982: 21) queda reflejado de manera espléndida en la moraleja que da fin a su poema de las abejas:

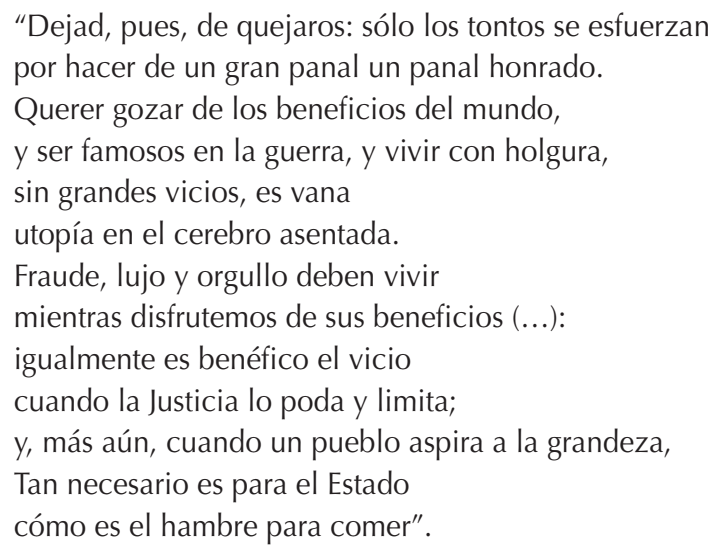

Para Mandeville todas las actividades económicas que dan forma a la opulencia de las sociedades encuentran su origen en el deseo de los seres humanos de satisfacer racionalmente, en el sentido utilitario del término, sus apetitos y pasiones egoístas. En sus quehaceres económicos ellos atienden exclusivamente a su propio interés. Sin embargo, estas mismas 
acciones económicas egoístas, que no buscan otra cosa que la obtención del mayor beneficio personal posible sin miramientos por los demás, contribuyen a la realización de la prosperidad material del conjunto de la sociedad. De este modo, "el bien público se realiza únicamente por una acción que no se orienta (conscientemente) hacia él" (Dumont, 1999: 100-101), y ello implica el hecho de que "el hombre no es social por naturaleza, pues sólo cuando no lo desea trabaja para el bien público" (Dumont, 1999: 101). El ser humano es por esencia egoísta, y la sociedad no es más que el espacio donde los individuos pueden beneficiarse del egoísmo de los otros:

"ni las cualidades amistosas ni los efectos simpáticos que son naturales en el hombre, ni las virtudes reales que sea capaz de adquirir por la razón y la abnegación, son los cimientos de la sociedad; sino que, por el contrario, lo que llamamos mal en este mundo, sea moral o natural, es el gran principio que hace de nosotros seres sociables, la base sólida, la vida y el sostén de todos los oficios y profesiones, sin excepción: es ahí donde hemos de buscar el verdadero origen de las artes y ciencias, y en el momento en que el mal cese, la sociedad se echará a perder si no se disuelve completamente" (Mandeville, 1982: 248) ${ }^{4}$.

A juicio de Dumont (1999: 93), "Mandeville ha encontrado que la satisfacción de las necesidades materiales del hombre es la única razón por la que los hombres viven en sociedad", es decir: "las relaciones entre hombres y cosas -las necesidades materiales- son primarias, las relaciones entre hombres -la sociedad-, secundarias". En este punto los planteamientos mandevillianos muestran continuidad respecto de las formulaciones de Locke, ello en tanto ambos autores sustentan la sociedad en lo económico. Sin embargo, esta posibilidad la funda Locke en un postulado que se encuentra totalmente ausente en la obra de Mandeville: la racionalidad moral de los seres humanos. Para el filósofo inglés, los seres humanos, en sus quehaceres económicos, no se guían exclusivamente por un egoísmo estrecho, sino que serían capaces de someter este egoísmo a un conjunto de reglas morales. Es en virtud de este supuesto como Locke puede resolver el problema de la coherencia de lo económico, así como también concebir este dominio como existiendo separadamente de lo político. Si los individuos en el espacio económico actuaran movidos sólo por consideraciones utilitarias no cabría esperar el funcionamiento ordenado, coherente, de esta esfera; por el contrario, la armonía económica sólo es posible gracias a la subordinación de la racionalidad utilitaria a una racionalidad de tipo moral. De este modo, como ya se dijo con anterioridad, la coherencia de lo económico perceptible en la obra de Locke es sólo una coherencia a medias. La transición de esta coherencia incompleta a una coherencia plena iba a depender de la emancipación de lo económico de la moralidad o, mejor dicho, del reconocimiento de lo económico como poseyendo un carácter moral propio. Este paso fundamental fue

4 El mal moral hace referencia a las pasiones y necesidades de los seres humanos, es decir, a todo aquello que desde el criterio rigorista se juzga negativamente, mientras que el mal natural corresponde a "la variedad de obstáculos que estorban y embrollan al hombre en la labor a que está constantemente dedicado, el procurarse lo que necesita: lo cual, en otras palabras, se llama ocuparse en la autoconservación" (Mandeville, 1982: 230). De esta forma, Mandeville demuestra que "la sociabilidad del hombre proviene solamente de dos cosas, a saber: la multiplicidad de sus deseos y la constante oposición con que tropieza para satisfacerlos" (Mandeville, 1982: 230). 
dado por Mandeville. Este autor ya no hace "referencia a la moral, a la 'sociedad ideal' del género humano, a la manera de Locke, sino a la sociedad concreta" (Dumont, 1999: 102). Y en esta realidad concreta los individuos no se comportan como Locke supone que lo hacen. Al contrario, nunca nadie actúa atendiendo a un concepto trascendente de moralidad. Toda acción halla su fundamento en el puro egoísmo utilitarista de los seres humanos. El gran mérito de Mandeville fue haber deducido la coherencia de lo económico o, en otras palabras, la identidad natural de los intereses, a partir de esta particular visión de la naturaleza humana:

"el hombre, dice Mandeville, es un mecanismo de pasiones egoístas interaccionándose. Afortunadamente, sin embargo, estas pasiones están de tal suerte compuestas y concertadas que, bajo el influjo de la sociedad, su aparente discordia se armoniza para lograr el bien público, aunque a primera vista parezca que su dominio amenaza anarquía. Esta concordancia, inmensamente complicada, no es el efecto de un esfuerzo premeditado, sino la reacción automática del hombre en sociedad" (Kaye, 1982: Ixviii).

Las acciones egoístas o viciosas contribuyen así a la realización del bienestar material, razón por la cual este accionar queda moralmente justificado. Tal como sostiene Dumont (1999: 105), "si el terreno económico escapa a la supremacía general y a la jurisdicción de la moral, es gracias al reconocimiento del hecho de que posee un carácter moral propio: el mecanismo automático trabaja para el bien público". El avance que muestra el pensamiento de Mandeville en comparación al de Locke radica en que este primer autor fue capaz de emancipar al individuo de las constricciones morales que limitaban su acción económica. Una vez lograda esta situación, la coherencia de lo económico alcanza una formulación más completa, cuestión que deja en claro que "el nacimiento de lo económico (...) y el pleno surgimiento del individualismo moderno son aspectos solidarios de un único y mismo fenómeno" (Dumont 1999: 135). Si lo económico posee una coherencia interna que le es inherente, entonces ahora la sociedad puede pasar a basarse por completo en este dominio, sin que sea necesario apoyarla en elementos externos; "la sociedad concreta se resuelve en su solo aspecto económico (y el bien social se identifica con la prosperidad o el desarrollo económico)" (Dumont 1999: 102-103), es decir, el orden instrumental de la economía equivale al orden social.

Así, en los planteamientos de Locke y de Mandeville se encuentran presentes todos los elementos necesarios para concebir lo económico como un dominio plenamente coherente. Sin embargo, estas piezas no se encontraban articuladas de modo tal que lo económico pudiera ser visto como objeto de estudio de una disciplina científica: la ciencia económica. Quien emprendió esta labor de sistematización y articulación fue Adam Smith, aunque muchas de sus ideas centrales ya hubieran sido adelantadas por autores precedentes. La formulación no sólo explícita, sino también científica, del postulado de la coherencia interna de lo económico se advierte por vez primera en la obra principal de Smith, "La riqueza de las naciones".

\section{SMITH Y LA PLENA COHERENCIA DE LO ECONÓMICO}

Adam Smith pensaba que "la actividad económica es la única actividad del hombre en que sólo se precisa de egoísmo: al perseguir únicamente sus intereses particulares los 
hombres están trabajando sin quererlo para el bien común; así entra en acción la famosa 'Mano invisible'" (Dumont 1999: 87). Para este autor, "cada individuo en particular se afana continuamente en buscar el empleo más ventajoso para el capital de que puede disponer. Lo que desde luego se propone es su propio interés, no el de la sociedad; pero estos mismos esfuerzos hacia su propia ventaja le inclinan a preferir, de una manera natural, o más bien necesaria, el empleo más útil a la sociedad como tal" (Smith, 1981: 400). En este punto la influencia de Mandeville es indudable (Dumont, 1999: 89). La noción de que el egoísmo trabaja para el bien común apunta en el sentido del reconocimiento del carácter moral inherente que tendría la acción económica, cuestión que le permitiría escapar a las trabas que le impone la moralidad general: “¿Qué enseña en efecto la moralidad, sino que el egoísmo debe subordinarse a fines superiores? La Mano invisible de Adam Smith cumple aquí una función que ha sido poco señalada. Es como si Dios nos dijera: 'Hijo mío, en esto no temas transgredir aparentemente mis mandamientos. He dispuesto todo de tal manera que puedes justificadamente prescindir de la moralidad en este caso particular'" (Dumont 1999: 87-88).

Ahora bien: había algo en el pensamiento de Mandeville que incomodaba a Smith. Si era un hecho cierto que las acciones egoístas tenían resultados sociales satisfactorios, ¿entonces por qué Mandeville persistía en calificarlas como viciosas? Smith en lo fundamental estaba de acuerdo con el análisis mandevilliano, "pero cuando Mandeville recurre a su despabilador rigorístico y dice 'todas estas cosas buenas se deben al vicio', todos contestaron (...): si es el vicio lo que en el mundo produce todo lo bueno, algo pasa en nuestra terminología; pues vicio semejante no es tal, sino virtud" (Kaye, 1982: Ixxi). Mandeville, si hemos de creer a Smith, "incurrió en el grave error de presentar toda pasión como si fuera realmente viciosa" (Franco, 1981: xx). Su adhesión formal al credo rigorista le impedía evaluar como virtuosas o buenas las acciones egoístas, aunque reconocía los resultados positivos que éstas acarreaban. Esto corresponde a lo que Kaye denomina como la "paradoja de Mandeville". La superación de esta paradoja constituía un paso que forzosamente tenía que darse para que se adoptara en plenitud una ética utilitarista, la cual "encierra la esencia de la actitud empírica científica moderna" (Kaye, 1982: Ixxi). Una vez desalojado el rigorismo, no iba a haber problemas en dar el calificativo de virtuosas o buenas a las acciones egoístas. Este paso fundamental se advierte en la obra de Smith, con lo que este autor resuelve un aspecto paradójico presente en las formulaciones mandevillianas.

A juicio de Halévy (1934: 90), la doctrina económica de Smith es la doctrina de Mandeville presentada en una forma que ya no es paradójica y literaria, sino que racional y científica. El carácter científico del pensamiento de Smith iba a depender no sólo de la resolución del problema terminológico presente en la obra de Mandeville, de lo que resultaría la plena adopción de una ética utilitarista, sino que también, y de manera primordial, de la demostración rigurosa del postulado de la coherencia interna de lo económico. La raíz de esta coherencia interna o de la identidad natural de los intereses se halla en un fenómeno al que Smith pone gran atención, y que constituye una parte fundamental de "La riqueza de las naciones": la división social del trabajo. Esta idea no contiene eso sí nada de original. Varios autores antes de Smith ya la habían adelantado, entre ellos el propio Mandeville. Sin embargo, "nadie, ni antes ni después de A. Smith, ha pensado nunca en atribuir una importancia semejante 
a la división del trabajo. Para él, ese elemento constituye prácticamente el único factor del progreso económico" (Schumpeter, 1971: 183). El ahínco que este autor puso en desarrollar toda una teoría acerca de este fenómeno permite reconocer en él al primero que formuló de manera explícita y científica el postulado de la coherencia interna de lo económico, delimitando así con claridad el objeto de estudio de la ciencia económica.

Como ya se ha dicho, el nacimiento de lo económico es indisociable del surgimiento del individualismo moderno, y por ello resulta obvio que la coherencia de este dominio se construye a partir del individuo, quien al perseguir su propio interés promueve sin pretenderlo la satisfacción de las necesidades ajenas en una mejor forma que un poder central (Franco, 1981: xxv). El individuo observable en la obra de Smith corresponde a un ser activo, el cual mediante su trabajo produce toda suerte de cosas útiles y necesarias para el diario vivir. La productividad del trabajo, según Smith, se halla condicionada por su división. Gracias a ella se produce un aumento considerable de los bienes y servicios disponibles para el consumo. Este fenómeno da lugar a una serie de circunstancias que explican el acrecentamiento de la productividad humana. En primer lugar, la división del trabajo contribuye a incrementar la destreza de cada trabajador, ahora especializado en una única tarea. También implica un ahorro de tiempo que, de no mediar esta división, se perdería al pasar de una ocupación a otra. Por último, trae consigo "la invención de un gran número de máquinas, que facilitan y abrevian el trabajo, capacitando a un hombre para hacer la labor de muchos" (Smith, 1981: 7). La mayor productividad del trabajo que acarrea su división se da al mismo tiempo que la distribución de los productos de este trabajo entre todos los individuos de una sociedad:

\begin{abstract}
"la gran multiplicación de producciones en todas las artes, originadas en la división social del trabajo, da lugar, en una sociedad bien gobernada, a esa opulencia universal que se derrama hasta las clases inferiores del pueblo. Todo obrero dispone de una cantidad mayor de su propia obra, en exceso de sus necesidades, y como cualquiera otro artesano, se halla en la misma situación, se encuentra en condiciones de cambiar una gran cantidad de sus propios bienes por una gran cantidad de los creados por otros; o lo que es lo mismo, por el precio de una gran cantidad de los suyos. El uno provee al otro de lo que necesita, y recíprocamente, con lo cual se difunde una general abundancia en todos los rangos de la sociedad" (Smith, 1981: 14).
\end{abstract}

Se observa aquí cómo en Smith se encuentran contenidos conceptos de producción y riqueza adecuados para dotar de coherencia a la esfera económica. Al ser humano se le atribuye un papel activo en la producción de riquezas, las cuales se entienden fundamentalmente en tanto objetos susceptibles de ser intercambiados (valores de cambio). Estas nociones, en conjunto con la división social del trabajo, permiten configurar una imagen de la sociedad entendida "como un inmenso sistema de cooperación, en el que cada uno no produce lo que necesita para sí mismo, sino lo que reclaman los demás" (Franco, 1981: xxvi).

Smith, como bien sostiene Halévy (1934: 91), vio en el principio de la división del trabajo una prueba del principio de la identidad natural de los intereses. Smith pensaba la división del trabajo no como una causa sino como un efecto del intercambio. Esto verifica la tesis fundamental según la cual el bienestar general no es el objeto consciente sino más bien una especie de producto automático de los intereses particulares. Ni la división del trabajo ni la 
prosperidad material que se deriva de ella son el efecto de la planificación humana; "esta división del trabajo -señala Smith (1981: 16)-, que tantas ventajas reporta, no es en su origen efecto de la sabiduría humana, que prevé y se propone alcanzar aquella opulencia que de él se deriva. Es la consecuencia gradual, necesaria aunque lenta, de una cierta propensión de la naturaleza humana que no aspira a una utilidad tan grande: la propensión a permutar, cambiar y negociar una cosa por otra". El cambio nace así del interés egoísta de los seres humanos, los cuales ven en este procedimiento una forma a través de la cual pueden satisfacer más plenamente sus necesidades. Es esta propensión al cambio común a todos los seres humanos la que trae consigo la reconciliación del interés general con los intereses privados. Es en virtud de ella como los egoísmos individuales se armonizan naturalmente. Y es que en la forma de cooperación inherente al intercambio y a la división social del trabajo no hay lugar para la benevolencia. Cuando un individuo le propone un intercambio a otro no invoca su bondad, sino que lo persuade de participar en la transacción apelando a su egoísmo: "Dame lo que necesito y tendrás lo que deseas, es el sentido de cualquier clase de oferta, y así obtenemos de los demás la mayor parte de los beneficios que necesitamos. No es la benevolencia del carnicero, del cervecero o del panadero la que nos procura el alimento, sino la consideración de su propio interés. No invocamos sus sentimientos humanitarios sino su egoísmo; ni les hablamos de nuestras necesidades, sino de sus ventajas" (Smith, 1981: 17). Los individuos, movidos por su propensión innata a intercambiar que encuentra su raíz en su egoísmo, deciden especializarse, dando lugar de este modo a la división del trabajo y a todos los resultados sociales positivos que ella conlleva. Esta es la cadena argumentativa que debe seguirse para la demostración del principio de la identidad natural de intereses que da forma a la coherencia interna de lo económico: "el cambio nace del interés egoísta; el interés egoísta -y no algo así como un deseo de cooperar- es así la causa de los beneficios aportados por la división del trabajo" (Dumont, 1999: 115). Una vez que ésta se instaló definitivamente, la vida de los seres humanos pasó a estar dominada por el intercambio, ello porque:

"sólo una pequeña parte de las necesidades de cada hombre se pudo satisfacer con el producto de su propia labor. El hombre subviene a la mayor parte de sus necesidades cambiando el remanente del producto de su esfuerzo, en exceso de lo que consume, por otras porciones del producto ajeno, que él necesita. El hombre vive así, gracias al cambio, convirtiéndose, en cierto modo, en mercader, y la sociedad misma prospera hasta ser lo que realmente es, una sociedad comercial" (Smith, 1981: 24).

Cuando recién empezó a practicarse la división del trabajo, la capacidad de cambio se vio sujeta a ciertas limitaciones; "es de suponer que un hombre tuviera de una mercancía más de lo que necesitaba, en tanto otro disponía de menos. El primero, en consecuencia, estaría dispuesto a desprenderse del sobrante, y el segundo, a adquirir una parte de este exceso. Mas si acontecía que este último no contaba con nada de lo que el primero había menester, el cambio entre ellos no podía tener lugar" (Smith, 1981: 24). Los seres humanos solucionaron este problema mediante la introducción de una mercancía particular, el dinero ${ }^{5}$,

5 "A fin de evitar inconvenientes de esta naturaleza -señala Smith (1981: 24)-, todo hombre razonable, en cualquier periodo de la sociedad, después de establecida la división del trabajo, procuró manejar sus negocios 
que lo que hace es crear la posibilidad de mayores intercambios (Aranzadi, 1999: 240). En una economía regida por el dinero cada uno de nosotros provee distintos bienes y servicios con miras a la obtención de una ganancia monetaria. Esta misma acción egoísta sirve al mismo tiempo, sin que el individuo actuante lo desee deliberadamente, a la satisfacción de las necesidades de los demás. El lugar donde se concretiza la identidad de intereses es el mercado; "el mercado -señala Naredo (2003: 136)- constituyó el terreno de juego en el que competían los átomos individuales y empresariales, intentando maximizar el placer o los beneficios o, si se quiere, constituyó el baño de aceite en el que podían desenvolverse sin rozamientos las fuerzas económicas, arrojando resultados óptimos para el conjunto del sistema". El mercado es el espacio donde se suceden las relaciones de intercambio, es decir, es ahí donde puedo obtener lo que necesito de la acción egoísta del otro. Gracias a él se coordinan las acciones económicas individuales, o sea, el mercado es la instancia en virtud de la cual la multiplicidad de relaciones de intercambio se desarrollan de una manera ordenada, acarreando los mejores resultados para todos.

Ahora bien: para que se concrete el intercambio, y con ello todos los beneficios que se pueden derivar de esta actividad, es fundamental saber cuánto de algo se intercambiará por cuánto de otra cosa. Como señala Dyke (1983: 42): "Si no podemos decidir entre nosotros cuánto de una cosa hay que intercambiar por cuánto de la otra, nunca vamos a poder completar la operación. Cuando sí decidimos cuánto de una cosa se intercambiará por cuánto de la otra, hemos establecido entre nosotros el precio de una cosa en función de la otra. Sin establecer el precio nunca podría tener lugar nuestra actividad de intercambio". De aquí, entonces, resulta claro que "para poder fijar los precios tenemos que establecer las cantidades de los diversos ítems intercambiados. Estas cantidades deben ser mensurables, de modo que si expresamos los precios en función de ellas disponemos de un sistema de medición auténticamente cuantitativo del valor de intercambio" (Dyke, 1983: 42). Smith habría hecho dos intentos para explicar los cambios que se producen en el valor de intercambio: la teoría del valor-trabajo y la teoría de la oferta y la demanda (Dyke, 1983: 43). Respecto de la primera, con ella Smith "nos recordaba que la mayoría de las cosas de valor para nosotros adquieren su valor -o aumentan su valor- debido al trabajo agregado" (Dyke, 1983: 43). Si el trabajo es en verdad la fuente más importante o la que más aporta al valor de las cosas, entonces éste es el común denominador del valor. De esta forma, "si el trabajo es un común denominador, tendríamos que poder expresar el valor de cualquier cosa en función del trabajo que requirió producir ese valor. Entonces podríamos decir que el valor real de algo es igual al monto de trabajo incluido en su producción" (Dyke, 1983: 44). Esta teoría da cuenta de la actividad de intercambio cuando propone que en todo intercambio lo que se intercambia son cantidades iguales de trabajo. En cuanto a la segunda teoría, ésta establece una relación "entre oferta y demanda, por un lado, y precio, por el otro" (Dyke, 1983: 49): "Adam Smith -sostiene Dyke (1983: 49)- da los fundamentos de la matemática de la teoría del precio cuando formula la relación de la oferta y la demanda con el precio de

de tal forma que en todo tiempo pueda disponer, además de los productos de su actividad peculiar, de una cierta cantidad de cualquier otra mercancía, que a su juicio escasas personas serían capaces de rechazar a cambio de los productos de su respectivo esfuerzo". 
la siguiente manera: a medida que aumenta la oferta, el precio tiende a decrecer; a medida que decrece la oferta, el precio tiende a aumentar; y a medida que aumenta la demanda, el precio tiende a aumentar; a medida que decrece la demanda, el precio tiende a decrecer". Considerado esto, tenemos la imagen del hombre económico racional u homo oeconomicus:

"Tengo que concebirme como un abastecedor de algunas cosas (puede ser sólo trabajo) y demandante de otras cosas. Proporcionaré cosas que sean valiosas para otros y demandaré cosas que sean valiosas para mí. Ahora bien, ¿cuál es la manera racional en que puedo realizarlo? Si funcionan las leyes de la oferta y la demanda, debo haber decidido que lo racional es tratar de ganar tanto valor como pueda y entregar tan poco valor como pueda. Además, todos los que intervienen en el mercado deben haber decidido la misma cosa (...) La regla de racionalidad implícita en este caso es: actúe de modo de obtener el máximo valor que pueda por el mínimo valor gastado. Se ha denominado 'hombre económico racional' al que actúa sobre la base de esta regla, y puede ser cualquiera de nosotros. Es importante percibir que las leyes de la oferta y la demanda y la imagen del hombre económico racional van de la mano. Cada una lleva a la otra" (Dyke, 1983: 49-50).

Cabe señalar que para Smith una de las condiciones requeridas para que todos realmente pudieran verse beneficiados por la división del trabajo y el intercambio era la existencia de un marco institucional adecuado. En este sentido, le daba gran trascendencia a la acción gubernamental a la hora de garantizar las libertades individuales y de administrar la justicia (Smith, 1981: 808). Al Estado le corresponde "garantizar la protección de cada miembro de la comunidad contra la violencia y opresión de cualquier otro miembro. Entre las 'leyes de la justicia' remarcadas por Smith se destacan: la prevención contra el fraude, la fuerza y las prácticas anticompetitivas para obtener ventajas sobre los demás; la garantía de la ejecución de contratos libremente acordados, y la defensa de los derechos de propiedad adquiridos de forma legítima" (Giannetti, 2000: 143). Del mantenimiento de la justicia depende entonces, evidentemente, "la vigencia de las reglas del juego del sistema de mercado" (Giannetti, 2000: 143); sin embargo, cabe advertir que, tal como señala Giannetti (2000: 143-144), "lo que aquí está en juego (...) es mucho más que el mercado. Del mantenimiento de la justicia depende, para Smith, el propio orden social (...) La justicia, por lo tanto, no es sólo el armazón legal del mercado. También es -lo que sin duda para Smith resulta todavía más importante- la condición mínima para la existencia del orden social".

Para Smith, el Estado debía limitarse a cumplir estas importantes funciones: no debía pasar más allá de ellas. Había que cuidarse de que el Estado adquiriera un poder mayor que el circunscrito a estos deberes. Y es que éste no debía intervenir activamente en el dominio económico, es decir, en ningún caso le correspondía dirigir la actividad económica privada. Esta instancia sólo debía garantizar a los individuos su propiedad privada y protegerlos de la violación de sus derechos. Hecho esto, el individuo quedaba en libertad para perseguir su interés personal como mejor le pareciera (Smith, 1981: 402). Y es que según este autor la búsqueda racional y libre de su propio interés conducía a los individuos, inevitablemente, y como guiados por una mano invisible, a promover el bien de los demás:

"como cualquier individuo pone todo su empeño en emplear su capital en sostener la industria doméstica, y dirigirla a la consecución del producto que rinde más valor, resulta 
que cada uno de ellos colabora de una manera necesaria en la obtención del ingreso anual máximo para la sociedad. Ninguno se propone, por lo general, promover el interés público, ni sabe hasta qué punto lo promueve. Cuando prefiere la actividad económica de su país a la extranjera, únicamente considera su seguridad, y cuando dirige la primera de tal forma que su producto represente el mayor valor posible, sólo piensa en su ganancia propia; pero en éste como en otros muchos casos, es conducido por una mano invisible a promover un fin que no entraba en sus intenciones. Mas no implica mal alguno para la sociedad que tal fin no entre a formar parte de sus propósitos, pues al perseguir su propio interés, promueve el de la sociedad de una manera más afectiva que si esto entrara en sus designios" (Smith, 1981: 402).

A juicio de Smith, de esta manera, el bienestar social resultaba automáticamente de las acciones egoístas de los seres humanos. El dominio económico se constituye así como un dominio ordenado y coherente, donde el gobierno no debe injerir activamente. En suma, los tres principios básicos contenidos en "La riqueza de las naciones" que darían cuenta del vínculo existente entre acción y orden social son los siguientes:

"en primer lugar, Smith supone que el impulso psicológico primordial en el hombre, como ser económico, es el afán de lucro. En segundo término supone la existencia de un orden natural en el universo, conforme al cual todos los empeños individuales, en el sentido del egoísmo, se conjugan para componer el bien social. Por último, sobre la base de estos postulados, concluye que el mejor programa consiste en dejar que el proceso económico siga por su cuenta; una tesis que ha llegado a ser conocida como laissez faire, liberalismo económico o no intervencionismo" (Lerner, 1981: xxxvi).

\section{CONCLUSIONES}

En Smith hallamos lo económico ya claramente delimitado, constituido como un dominio independiente y coherente a la vez, separado tanto de lo político como de lo moral, y por tanto objeto de estudio de una disciplina particular: la ciencia económica. Las ideas básicas de Adam Smith fueron acogidas por economistas posteriores, quienes se encargaron de refinar algunos de sus postulados, pero sin variar la estructura fundamental de su pensamiento. Puede decirse que con Smith no sólo surge una disciplina, sino que también emerge un punto de vista omnicomprensivo, que desde sus particulares supuestos pretende convertirse en explicación de todos los aspectos de la realidad social, incluso de aquellos problemas que han sido considerados como el terreno de estudio propio de la sociología, como son los problemas de la acción humana y del orden social. Lo que hace Adam Smith es derivar el orden social a partir del accionar en el ámbito del mercado de individuos concebidos en tanto hombres económicos racionales. Siguiendo a Descouvieres (1998: 23-24), el homo oeconomicus propuesto por Smith presenta las siguientes características: "Actúa exclusivamente por interés personal; sólo obedece a la razón, procurando alcanzar el máximo de satisfacción con el mínimo esfuerzo o sacrificio; es universal, es decir, no posee peculiaridades regionales y está siempre informado perfectamente de todos los datos del mercado; vive sólo el presente, es, por lo tanto, atemporal; no recibe la influencia de otros hombres, es perfectamente aislado y libre, sin recibir la influencia social". 
La economía que recoge los planteamientos smithianos postula así que, en la esfera económica, de una multiplicidad de individuos que actúan según patrones utilitarios no se deriva el caos, sino una realidad ordenada, ello en la medida en que quien actúa racionalmente en función de su interés personal contribuye, sin quererlo o desearlo premeditadamente, a la realización del interés general. Lo económico se constituye de esta manera como el espacio donde los individuos encuentran una manera provechosa de utilizarse mutuamente para sus propios fines, como el espacio donde las acciones humanas quedan perfectamente coordinadas en base al propio interés. En definitiva, como el lugar donde se constituye el orden social en el cual descansa la sociedad entera. La corriente principal de la economía cree haber resuelto el problema del orden social a partir de su particular visión de la naturaleza humana.

\section{BIBLIOGRAFÍA}

Aranzadi del Cerro, Javier (1999): Liberalismo contra liberalismo: análisis de las obras de Ludwig von Mises y Gary Becker, Unión Editorial, Madrid.

Dawe, Alan (2001): "Las teorías de la acción social", en Tom Bottomore y Robert Nisbet (comp.): Historia del análisis sociológico, Amorrortu, Buenos Aires, pp. 412-476.

Descouvieres, Carlos (1998): Psicología económica, Editorial Universitaria, Santiago.

Dumont, Louis (1999): Homo aequalis. Génesis y apogeo de la ideología económica, Taurus, Madrid.

Dyke, Charles E. (1983): Filosofía de la economía, Paidós, Buenos Aires.

Enguita, Mariano F. (1998): Economía y sociología. Para un análisis sociológico de la realidad económica, Siglo XXI, Madrid.

Figueroa, Rodrigo (2002): Desempleo y precariedad en la sociedad de mercado, Frasis, Santiago.

Fontaine, Juan Andrés (1981): "El punto de vista económico", Estudios Públicos, 2, pp. 1-17.

Franco, Gabriel (1981): "Estudio preliminar", en Adam Smith: Investigación sobre la naturaleza y causas de la riqueza de las naciones, Fondo de Cultura Económica, México.

Giannetti, Eduardo (2000): ¿Vicios privados, beneficios públicos? La ética en la riqueza de las naciones, Paidós, Buenos Aires.

Halévy, Elie (1934): The growth of philosophic radicalism, Faber and Faber, London.

Hayek, Friedrich (1982): "Los principios de un orden social liberal”, Estudios Públicos, 6, pp. 179-202.

(1986): "El mensaje de Adam Smith en el lenguaje actual”, Estudios Públicos, 23, pp. 89-92.

Holton, Robert J. (1992): Economy and society, Routledge, London.

Ingrao, Bruna y Giorgio Israel (1990): The invisible hand. Economic equilibrium in the history of science, MIT Press, London.

Irigoin, Alfredo (1987): "La vigencia de Adam Smith", Estudios Públicos, 26, pp. 193-210.

Kaye, F.B. (1982): "Introducción", en Bernard Mandeville: La fábula de las abejas o los vicios privados hacen la prosperidad pública, Fondo de Cultura Económica, México.

Laski, Harold J. (1987): El liberalismo europeo, Fondo de Cultura Económica, México.

Lerner, Max (1981): "Introducción", en Adam Smith: Investigación sobre la naturaleza y causas de la riqueza de las naciones, Fondo de Cultura Económica, México. 
Locke, John (1997): Dos ensayos sobre el gobierno civil, Espasa Calpe, Madrid.

Mandeville, Bernard (1982): La fábula de las abejas o los vicios privados hacen la prosperidad pública, Fondo de Cultura Económica, México.

McPherson, C.B. (1979): La teoría política del individualismo posesivo: de Hobbes a Locke, Fontanella, Barcelona.

Muller-Armack, Alfred (1967): Genealogía de los estilos económicos, Fondo de Cultura Económica, México.

Mundell, Robert A. (1972): El hombre y la economía, Amorrortu, Buenos Aires.

Myrdal, Gunnar (1961): El elemento político en el desarrollo de la teoría económica, Gredos, Madrid.

Naredo, José Manuel (2003): La economía en evolución. Historia y perspectivas de las categorías básicas del pensamiento económico, Siglo XXI, Madrid.

Schumpeter, Joseph (1971): Historia del análisis económico, Fondo de Cultura Económica, México.

Sen, Amartya K. (1977): "Rational fools: a critique of the behavioral foundations of economic theory", Philosophy and Public Affairs, 6 (4), pp. 317-344.

Smith, Adam (1981): Investigación sobre la naturaleza y causas de la riqueza de las naciones, Fondo de Cultura Económica, México.

Recibido: 01-11-2010

Aceptado: 13-10-2011 